\title{
Os investimentos estatais na geração de hidrogênio no Brasil
}

\author{
Sérgio Aldrighi Raffi', Angélica Massuquetti², Tiago Wickstrom Alves ${ }^{3}$ \\ I Mestre em Economia pelo Programa de Pós-Graduação em Economia (PPGE) - Universidade do Vale do Rio dos Sinos (UNISINOS) \\ 2 Professora do Programa de Pós-Graduação em Economia (PPGE) - Universidade do Vale do Rio dos Sinos (UNISINOS) \\ 3 Professor do Programa de Pós-Graduação em Economia (PPGE) - Universidade do Vale do Rio dos Sinos (UNISINOS)
}

\section{Resumo}

O objetivo deste artigo foi analisar a política de investimento estatal na geração de hidrogênio no Brasil a partir de 2002. A partir da metodologia de pesquisa bibliográfica, constatou-se que os investimentos brasileiros em hidrogênio estão direcionados para dois segmentos: gerar energia nas células a combustível para suprir veículos e unidades estacionárias e gerar hidrogênio com o objetivo de produzir um combustível com um menor teor de enxofre. Por fim, a preocupação com o meio ambiente tem suscitado a procura por combustíveis mais eficientes e menos poluentes. Neste sentido, os investimentos estatais brasileiros em hidrogênio estão buscando a redução dos impactos ambientais ocasionados por combustíveis fósseis.

Palavras Chave: Hidrogênio; Células a combustível; Economia do hidrogênio.

\begin{abstract}
The aim of this study was to analyze the policy of state investment in hydrogen generation in Brazil since 2002. From the research methodology literature, it was found that Brazilian investments in hydrogen are directed to two segments: power generation in fuel cells to supply vehicles and stationary units and generate hydrogen with the goal of producing a fuel with a lower content of sulfur. Finally, concern for the environment has raised the demand for more fuel efficient and less polluting. In this sense, the Brazilian state investments in hydrogen are seeking to reduce the environmental impacts caused by fossil fuels.
\end{abstract}

Keywords: Hydrogen; Fuel Cells; Hydrogen Economy. 


\section{INTRODUÇÃO}

O aumento da quantidade de veículos automotores e, por consequência, da alta incidência de detritos gerados pela queima de combustíveis fósseis têm promovido o debate, por parte de ambientalistas, de políticos e de pesquisadores, acerca da necessidade de uma nova matriz energética, estimulando o investimento em pesquisas sobre energia limpa. O hidrogênio é uma fonte de energia limpa, pois não gera a emissão de detritos poluentes, o que vem ao encontro das questões ambientais atuais.

Os acordos tecnológicos e as trocas de experiências entre os países, nos últimos anos, têm revelado a busca por soluções quanto aos problemas ambientais. A tecnologia do hidrogênio, portanto, surge como uma alternativa energética e tem sido estudada, nas últimas décadas, por diferentes nações, como Estados Unidos da América (EUA), Japão e países europeus, que procuram fontes de energia limpa, não poluentes e renováveis.

A partir de 2002, no Brasil, o Ministério de Ciência de Tecnologia (MCT) iniciou o desenvolvimento da economia do hidrogênio no país. Ou seja, o MCT realizou a classificação para as competências científicas e tecnológicas referentes à tecnologia do hidrogênio, tendo como fato desencadeador as pesquisas na área da produção de hidrogênio e de células a combustível desenvolvidas em diferentes instituições, com financiamento de agências de pesquisa ou empresas (LABORDE et al., 2010). As células a combustível são, segundo Lellis et al. (2010), equipamentos capazes de gerar energia elétrica a partir do hidrogênio.

No Brasil, o uso do hidrogênio para fins de geração de energia ainda é reduzido, sendo sua produção consumida quase que totalmente na indústria. Já a produção de hidrogênio para fins industriais tem expressividade no país e no ano de 2002, por exemplo, alcançou 425 mil toneladas. Em 2004, a Petróleo Brasileiro S/A (PETROBRAS) produziu mais de 180 mil toneladas de hidrogênio (FOSTER et al., 2011). Há evidências, de acordo com os autores, de que o Brasil se tornará o maior produtor de hidrogênio do mundo, tendo por base as fontes renováveis de energia.

Para Laborde et al. (2010), a produção do hidrogênio no Brasil se dará, preferencialmente, a partir do etanol, sendo que outras fontes energéticas, como biomassa e fontes renováveis (solar, eólica e hidráulica) também serão relevantes. Os investimentos em hidrogênio, segundo CGEE (2010), apresentam grandes oportunidades para o país, tendo em vista que o estímulo destas tec- nologias por intermédio de instituições governamentais e empresariais deverá gerar frutos vultosos, entre eles: diminuição de impactos ambientais na geração e na utilização de energia; aumento da segurança energética; melhoria do aproveitamento dos recursos naturais; desenvolvimento regional; desenvolvimento de parque industrial competitivo; e geração de empregos.

O hidrogênio, deste modo, apresenta-se como uma importante alternativa na geração de energia, já que pode ser produzido, armazenado e convertido diretamente em eletricidade por meio de células a combustível. O hidrogênio pode, ainda, ser utilizado na melhoria dos combustíveis fósseis usados atualmente, com isso, tornando-os mais eficientes e menos poluentes. Este artigo, portanto, pretende contribuir para o conjunto de pesquisas acerca do hidrogênio no campo acadêmico brasileiro, destacando, em especial, a importância que os investimentos estatais brasileiros têm para este momento de discussão acerca da matriz energética nacional e mundial.

Nesse sentido, o objetivo geral deste artigo é analisar a política de investimento estatal na geração de hidrogênio no país a partir de 2002 e utilizou-se a metodologia de pesquisa bibliográfica. $\mathrm{O}$ artigo está dividido em cinco seções, considerando a Introdução e as Considerações Finais. Na segunda seção é contextualizada a economia do hidrogênio e são apresentados os principais estudos sobre o hidrogênio no Brasil. Na terceira são identificados os investimentos em hidrogênio no mundo. Na quarta seção são analisados os investimentos estatais em hidrogênio no país. Por fim, na última seção, são apresentadas as conclusões desta pesquisa.

\section{A PESQUISA SOBRE HIDROGÊNIO NO BRASIL}

Os investimentos em pesquisa energética a partir do hidrogênio têm gerado bons resultados, visto que constantes avanços tecnológicos tanto na obtenção quanto no armazenamento e na conversão do hidrogênio em células combustíveis são uma realidade. Houve também avanço no meio acadêmico, com o aumento de artigos e de publicações referentes às pesquisas sobre hidrogênio na última década, mostrando a relevância destes estudos (LELLIS et al., 2010). Nesta seção é contextualizada a economia do hidrogênio e são apresentados os principais estudos sobre o hidrogênio no Brasil. 


\section{I A ECONOMIA DO HIDROGÊNIO}

Cruz (2010) afirma que a utilização do hidrogênio como vetor energético e a concepção de um sistema energético, tendo por base o hidrogênio, não são ideias novas. Até os anos 1960, em muitos países, o hidrogênio era utilizado como fonte de energia, iluminação pública e, nas residências, para aquecimento e na preparação de alimentos. Essa ideia de um vasto uso do hidrogênio no alicerce energético dos sistemas econômicos foi estabelecida no momento em que o petróleo enfrentava sua crise (década de 1970), mas não houve continuidade após este período. Com o efeito estufa e o desenvolvimento das células a combustível, contudo, a economia do hidrogênio ressurgiu. A geração de energia elétrica, tendo por base o hidrogênio, com o aperfeiçoamento das células a combustível, superou o uso em aparelhos estacionários e cunhou a possibilidade de sua utilização energética em outros setores, como o transporte.

De acordo com Matos (2009), no ano de 1987, o Relatório de Brundtland definiu o conceito de desenvolvimento sustentável, promovendo a ampliação do debate acerca da dimensão ambiental. A partir de então, a economia do hidrogênio, segundo CGEE (2010), passou a apresentar-se como um novo paradigma, já que os principais motivos para os investimentos neste vetor são a segurança energética e a diminuição dos impactos ambientais.

Num momento em que a preocupação com a preservação do meio ambiente está tão presente, surge também a expressão descarbonização da economia que prega a utilização de combustíveis menos poluentes não vinculados ao carbono. Rohrich (2008) afirma que para uma redução nas emissões de $\mathrm{CO} 2$, deve-se empregar o hidrogênio como vetor energético, sendo a célula a combustível a tecnologia que converte o hidrogênio em eletricidade e que pode ser utilizada para gerar energia em estações fixas e para movimentar veículos. A autora aborda tanto o hidrogênio quanto as células a combustível como substitutos potenciais para os combustíveis fósseis, mas alerta que os benefícios originados dessa troca não compreenderão os custos, pois ambos terão competitividade, em comparação ao atual regime, no momento em que o hidrogênio e a célula a combustível chegarem a uma economia de escala.

Segundo Matos (2009), no ano de 2003, em Washington (EUA), constituiu-se a International Partnership for the Hydrogen Economy (IPHE) com a finalidade de formar parceiros internacionais para fortalecer a economia do hidrogênio. Através deste órgão, as nações participantes empenharam- -se em consolidar a economia do hidrogênio por meio de investimentos em hidrogênio e em células a combustível. Dentre os países da América Latina, o Brasil é o único que compõe o IPHE.

Em 2005, após oito anos de sua preparação, o Protocolo de Quioto passou a vigorar, tendo como escopo central reduzir as emissões de $\mathrm{CO} 2$ na atmosfera. Inúmeros países assinaram o Protocolo, com exceção da Austrália, da África do Sul e, especialmente, dos EUA, que é um grande emissor dos gases que afetam a atmosfera, ficando atrás somente da China (MATOS, 2009).

$\mathrm{Na}$ atualidade, observa-se um acréscimo no número de especialistas que veem uma relação entre os gases de efeito estufa (GEE) liberados pela queima de combustíveis fósseis e a elevação da temperatura do planeta. Este fato, somado à falta de reservas fósseis de energia e à elevação do consumo e dos preços do petróleo, tem sido o motivo para se pensar no uso de fontes renováveis de energia (CGEE, 2010). Além disso, a demanda por fontes de energia com baixo teor de poluição vem ao encontro das legislações ambientais atuais.

Segundo Almeida (2005), a tecnologia que utiliza as células a combustível geram emissões mínimas quando comparada com outras fontes energéticas. De acordo com o autor, a utilização de combustíveis fósseis gera $11,29 \mathrm{~kg}$ de emissões por $1.000 \mathrm{kWh}$, entre elas óxido de nitrogênio (NOx), óxido de carbono (CO), óxido de enxofre (SOx) e partículas, de energia gerada. A tecnologia que utiliza as células a combustível, por outro lado, emite apenas $0,02 \mathrm{~kg}$ de emissões por $1.000 \mathrm{kWh}$ de energia gerada.

O hidrogênio pode ser obtido de fontes renováveis de energia ou de fontes não renováveis, proporcionando uma segurança energética, pois cada país pode obtê-lo a partir de suas fontes locais. Atualmente, quase todo o volume de hidrogênio produzido no mundo é utilizado com finalidades químicas $(87 \%)$, sendo a maior parte oriunda de combustíveis de origens fósseis (96\%). Desta forma, permanece sua vinculação aos hidrocarbonetos provenientes de petróleo, ocasionando um aumento do efeito estufa. As pesquisas em hidrogênio com o objetivo de preservar o meio ambiente são, portanto, importantes, já que seu uso afeta os mais variados campos econômicos, como industrial, comercial, habitacional e transporte (MATOS, 2009).

De acordo com Cruz (2010), o gás natural é, atualmente, a principal fonte de produção do hidrogênio. A água tem uma participação de apenas $4 \%$ na produção e é utilizada nesse processo por meio de eletrólise, onde seus átomos são quebrados através da passagem de uma corrente elétrica. A 
água é a mais abundante de todas as fontes, mas é a menos utilizada. Segundo Bezerra Filho (2008), o hidrogênio também pode ser obtido pela eletrólise a partir de energia solar, de energia proveniente de hidrelétricas ou de energia oriunda dos geradores eólicos. Também tem origem na reforma a vapor de fontes fósseis ou biocombustíveis, o etanol e a biomassa, ou ainda a partir de outras formas de produção como, por exemplo, as que utilizam o lixo urbano. Conforme Carvalho (2009), também se obtém o hidrogênio a partir de restos agrícolas e de dejetos oriundos da indústria madeireira pelo processo denominado pirólise e reforma.

$\mathrm{Na}$ indústria, o hidrogênio encontra uma variada gama de aplicações, que vão desde a fabricação de produtos fármacos, a fabricação de semicondutores e a geração de energia térmica ou elétrica (quando utilizado como insumo nas células a combustível). Uma menor parte do hidrogênio que é produzida no mundo é usada para fabricar metanol, que é empregado em diferentes produtos, como plásticos, tintas, explosivos, solventes ou transformado em formaldeído. A produção de amônia gasta em torno de $50 \%$ da produção de hidrogênio, já o processamento de petróleo utiliza aproximadamente $40 \%$ da produção de hidrogênio (CRUZ, 2010).

Para Foster et al. (2011), o hidrogênio pode ser utilizado em aplicações denominadas estacionárias, na geração de energia para hospitais e sistemas que não devam sofrer interrupção e nos sistemas de coogeração, atendendo grupos isolados e armazenagem energética. O uso do hidrogênio em veículos se encontra direcionado para transporte urbano, sendo que a maior parte desses se move por meio de motores que consomem óleo diesel. Um setor também relevante é o de máquinas agrícolas. De acordo com os autores, o hidrogênio produzido do etanol, do gás natural e da gaseificação da biomassa tem o poder de substituir, em parte, os motores que utilizam óleo diesel, sendo uma opção com maior eficiência e menor poluição. Para Braga (2009), a geração distribuída de energia apresenta muitas vantagens, sendo este um modelo ou modo de utilização do hidrogênio nas chamadas células a combustível com o objetivo de atender a demanda de energia em comunidades distantes.

Segundo CGEE (2010), atualmente, há interesse no uso do hidrogênio para movimentar veículos e na geração distribuída de energia elétrica. O método que se obtém melhores resultados é o conjunto de células a combustível usado nos veículos, cuja emissão local é quase nula. Para Laborde et al. (2010), o hidrogênio, quando uti- lizado em células a combustível na produção de energia elétrica, atinge uma eficiência energética muito superior à obtida apenas por sua queima. Sistemas de energia que necessitam funcionamento interrupto são consumidores em potencial da geração de energia a partir de células a combustível, como hospitais e bancos.

Segundo Lellis et al. (2010), a utilização de combustíveis com menos carbono tem sido uma tendência observada nos últimos 20 anos e seguindo-se essa premissa da descarbonização da economia, o mundo poderá conhecer o fim da era do carbono como combustível, um papel onde o hidrogênio assume sua importância como gerador de energia. O Brasil, por sua vez, tem potencialidade na produção de hidrogênio, tendo por base várias fontes energéticas, tornando sua matriz energética mais equilibrada ainda. Para Gatto (2010), o Brasil tem todas as características necessárias para o bom incremento de sua matriz energética, tecnologia adequada por seu conhecimento em fontes renováveis fartas e fatores economicamente viáveis.

Assim, uma alternativa para a redução dos transtornos causados pela queima de combustíveis fósseis está na utilização de outras fontes para a geração de energia, a chamada energia limpa, sendo o hidrogênio uma delas (LABORDE et al., 2010). De acordo com Assis et al. (2008), frente à probabilidade da escassez de fontes energéticas oriundas do petróleo e diante dos impactos ambientais e de saúde pública causados por essas práticas, faz-se necessário promover o desenvolvimento de novas matrizes energéticas com menores impactos ambientais, afirmando, também, que o hidrogênio é uma dessas opções.

As universidades e os centros de pesquisa no mundo têm trabalhado no intuito de desenvolver pesquisas sobre o hidrogênio, montadoras de grande porte possuem protótipos que usam o hidrogênio na forma de combustível e empresas do setor petrolífero do mundo todo procuram adaptar-se à nova concepção energética e diversificam seu portfólio, como a British Petroleum (BP). Os investimento realizados pelo setor público tem aumentado nos últimos 10 anos com o objetivo de instalar a infraestrutura indispensável para distribuir o hidrogênio até os consumidores. Determinados países da União Europeia (UE) têm programas relacionados à ampliação do hidrogênio para uso como combustível em veículos há mais de uma década, como Holanda, França e Alemanha. Os EUA têm elevado os investimentos relacionados à utilização do hidrogênio como vetor de energia, sendo que no campo de pesquisa e de infraestrutra, 
o Departamento de Energia Norte-Americano (DOE) tinha um orçamento de US\$ 200 milhões em 2009 e havia estimativa de que, no período 2010-2013, esse montante se aproximaria à US\$ 1 bilhão (CRUZ, 2010).

As pesquisas nessa área são relevantes, pois, segundo Cruz (2010), a grande parte do hidrogênio que é obtida atualmente tem origem em combustíveis fósseis, portanto, poluente. Para Lellis et al. (2010), o hidrogênio produzido pode ser utilizado na geração de energia de forma eficiente nas células a combustíveis, já que seu uso como agente transmissor de energia diminui a demanda por outro combustível, reduzindo o impacto ambiental gerado pelo excesso da produção de outro material a ser utilizado. Com isso, se reduz a emissão de poluentes nos centros urbanos, bem como se gera oportunidade para uma nova indústria nos países. De acordo com CGEE (2010), a obtenção de energia elétrica por meio de células a combustível, que não produzem gases de efeito estufa, é adequada para uma nova matriz energética, pois o subproduto originado de seu uso é apenas a água. Quando queimado em motores a combustão interna, as emissões desses gases também são minimizadas significativamente.

\subsection{A EVOLUÇÃO DA PRODUÇÃO CIENTÍFICA SOBRE HIDROGÊNIO}

De acordo com Santos (2008), o uso energético do hidrogênio jamais foi tão analisado e recomendado como recurso de diversos problemas no quadro energético mundial como na atualidade. Os países mais desenvolvidos se destacam nessas pesquisas em razão de suas competências para empreender e pela disponibilidade de recursos para os investimentos, especialmente na ampliação tecnológica das células a combustível.

Nas últimas décadas, como afirma Santos (2008), houve um crescente número de publicações científicas voltadas ao hidrogênio e às células a combustível. Um momento crucial para o aumento dessas pesquisas foi a crise do petróleo na década de 1970, que gerou o envolvimento de pesquisadores, apoiados por empresas privadas ou públicas, com o estudo de alternativas ao setor energético em crise. Tal fato leva a crer que o mundo está cada vez mais voltado às novas tecnologias, que visam a geração de energia considerada limpa, ou seja, com poucos ou nenhum poluente emitido. A tecnologia para a obtenção de hidrogênio se encontra em desenvolvimento, sendo que para isso estuda-se a possibilidade de sua obtenção até mesmo a partir de lixo urbano, que seria uma solução para o lixo nas grandes cidades. Quanto às células a combustível, estas se encontram em fase de aprimoramento, com a finalidade de produção em escala de células eficientes e baratas para atender às mais variadas necessidades em termos energéticos.

A produção científica do Brasil, no período 1970-2006, no total de estudos sobre o tema, foi de 27 publicações sobre hidrogênio e de 33 sobre células a combustível, aparecendo na $17^{\mathrm{a}}$ posição do ranking mundial. Os EUA (329 publicações sobre hidrogênio e 705 sobre células a combustível) lideram o ranking mundial, seguidos por Alemanha (144 publicações sobre hidrogênio e 252 sobre células a combustível), Japão (129 publicações sobre hidrogênio e 256 sobre células a combustível) e Reino Unido (83 publicações sobre hidrogênio e 173 sobre células a combustível). Também é possível afirmar que as publicações sobre células a combustível superam os estudos sobre o hidrogênio (SANTOS, 2008).

No Brasil, as pesquisas na área da produção de hidrogênio e de células a combustível foram desenvolvidas em diferentes instituições, com financiamento de diferentes agências de pesquisa ou empresas. Isto fez com que o MCT realizasse uma classificação para as pesquisas científicas e tecnológicas nestas áreas (LABORDE et al., 2010). Segundo os autores, houve a evolução do número de artigos publicados no Brasil sobre hidrogênio e células a combustível, em especial, a partir de 2002.

Por fim, conforme Santos (2008), a utilização do hidrogênio como fonte de energia teve início a partir da metade da década de 1970, fato que ocorreu no momento em que acontecia a crise do petróleo. Porém, com a diminuição dos preços do petróleo na metade dos anos 1980, ocorreu uma redução do interesse pelo hidrogênio. A partir dos anos 1990, com o aumento de questões de cunho ambiental, propondo a não degradação do meio ambiente pela ação do homem e os cuidados com os detritos industriais, e as legislações referentes ao tema, motivadas pelo Protocolo de Quito, a questão do hidrogênio como fonte energética foi retomada e, por consequência, das células a combustível.

\subsection{OS ESTUDOS EMPÍRICOS SOBRE HIDROGÊNIO NO BRASIL}

Moreira (2005) realizou uma avaliação dos aspectos ambientais da geração de energia através de termoelétricas a gás natural. Seu estudo foi desenvolvido, tendo-se por base a classificação e a apreciação da literatura referente ao assunto e dados de 1970 a 2003. Suas principais conclusões foram que houve uma elevação no nível de pre- 
ocupação e de empenho dos cientistas quanto à necessidade de produzir e gastar energia sustentavelmente. Para a autora, não há apenas um caminho a ser seguido, mas muitas são as alternativas para a solução de questões de ordem energética.

Santos (2008) analisou as tendências tecnológicas das células a combustível para uso do hidrogênio derivado de petróleo e de gás natural, no período 1974-2006, em bases de dados do universo científico-tecnológico (H2-CaC-Cient-Tec) e do universo governamental (H2-CaC-Gov). A autora concluiu, por meio de análise estatística, que houve uma redução do número de artigos e de publicações referentes ao tema hidrogênio e células a combustível (número de artigos e publicações a partir das palavras-chave analisadas) com a diminuição dos preços internacionais do petróleo, mas não a ponto de voltar este empenho aos planos anteriores, apesar de ainda estar presente em razão das questões ambientais, como o efeito estufa.

Rohrich (2008) estudou a descarbonização do regime energético dominante e as perspectivas para a economia do hidrogênio no Brasil a partir de dados do período 1983-2005. Em relação à política brasileira para a economia do hidrogênio, o autor analisou seus obstáculos e suas oportunidades, colocando em evidência que as barreiras para a alteração no regime energético ainda não foram ultrapassadas nem mesmo no campo tecnológico. Por fim, afirmou que ainda há problemas de ordem institucional e econômico para que ocorra a modificação de regime.

Bernardi Junior (2009) analisou as principais fontes de energia renováveis, bem como avaliou a produção de resíduos das regiões brasileiras (por estado). $\mathrm{O}$ autor também analisou o potencial de produção de hidrogênio pela biomassa, por célula fotovoltaica e pela energia eólica e os custos da energia obtida. A metodologia empregada pelo autor foi exploratória, documental e quantitativa. A produção de hidrogênio pela biomassa através da gaseificação desta ou ainda pela fotovoltaica e pela eólica são alternativas que oferecem momentos de produção que, em grande parte do tempo, não são compatíveis com os períodos de demanda. Desta forma, a célula a combustível se enquadra às necessidades da sociedade, podendo utilizar hidrogênio como vetor energético.

Braga (2009) realizou a análise da viabilidade econômica da integração de sistemas de célula a combustível, nas plantas de cloro-soda, para utilização do hidrogênio gerado no processo. Sua metodologia foi exploratória, documental e quantitativa, partindo da hipótese de que, na indústria de cloro-soda, o uso do hidrogênio obtido no processo pode ser utilizado para a geração de energia elétrica e, com isso, trazer vantagens.

Matos (2009) analisou os investimentos financeiros em projetos de células a combustível e hidrogênio no Brasil. A partir de dados compreendidos entre 1999 e 2007, a metodologia empregada pela autora foi Bottom-up e Top-dow, compatibilidade de dados de comparação entre os investimento no Brasil e no mundo. A autora afirmou que a agência de fomento que mais investiu na área do hidrogênio foi a Financiadora de Estudos e Projetos (FINEP), com R \$ 40,63 milhões, seguida pela Fundação de Amparo à Pesquisa do Estado de São Paulo (FAPESP), com R \$ 26,99 milhões, pela P\&D Aneel, com R $\$ 21,32$ milhões, e pelo Conselho Nacional de Desenvolvimento Científico e Tecnológico (CNPq), com R \$ 8,93 milhões.

Cruz (2010) estudou a produção de hidrogênio em refinarias de petróleo - avaliação energética e custo de produção - e realizou um levantamento bibliográfico sobre o hidrogênio e as perspectivas futuras dos seus diferentes processos de obtenção. O autor observou que os custos obtidos pela reforma a vapor são sensíveis aos custos do gás natural usado como matéria prima no processo. Essa é uma indicação de que o uso de plantas de gaseificação na geração de hidrogênio podem trazer benefícios de ordem econômica, tendo em vista que o carvão ou coque poderão sofrer impactos sobre seu preço atual em decorrência de uma elevação na demanda por energéticos, particularmente, no Brasil. O autor alcançou custos de obtenção de hidrogênio a partir de diferentes métodos, que podem servir de base para estudos posteriores, como a eletrólise.

D'Alessandro (2011) analisou a metodologia de gerenciamento de risco do hidrogênio, investigando a infraestrutura da geração de hidrogênio e os riscos de instalação, adequação do processo, vazamento, parada total do sistema de produção, despressurizarão e falta de ventilação para a expansão de possíveis perdas. Outros riscos também foram caracterizados para serem estudados e inseridos num estudo mais completo e abrangente. $\mathrm{O}$ hidrogênio é considerado altamente inflamável, mas não existe registro de perdas ou eventos catalogados com acidentes na obtenção ou uso do hidrogênio no Brasil. Desta forma, os cuidados necessários no momento de se identificar e gerenciar os riscos devem ser feitos com a máxima precisão, usando-se a alta tecnologia disponível.

Em alguns estudos, observa-se a preocupação em se utilizar o hidrogênio de uma forma sustentável, minimizando seus custos de obtenção. $\mathrm{O}$ hidrogênio, apesar de ser um gás altamente 
inflamável, não apresenta registro de acidentes em sua obtenção e uso no Brasil, o que vem a fortalecer outros estudos acerca de sua utilização e de seus benefícios.

\section{OS INVESTIMENTOS EM HIDROGÊNIO NO MUNDO}

Os problemas ambientais causados pelos combustíveis fósseis têm gerado debates políticos e acadêmicos e investimentos de países na geração de energia limpa. Os convênios entre os países têm ocorrido na forma de acordos tecnológicos e de trocas de experiências. A preocupação tanto de caráter ambiental quanto econômico leva a repensar a matriz energética, não apenas no Brasil, mas no mundo. Nesta seção são apresentados os investimentos em hidrogênio no mundo.

\section{I O HIDROGÊNIO NOS EUA}

Os EUA se encontram em estágio avançado na tecnologia de produção e de utilização do hidrogênio nas células combustíveis. O Departamento de Energia do país tem dado continuidade ao programa de construção destas células a fim de superar barreiras tecnológicas e econômicas. Com isto, pretende atingir a comercialização destas células e tecnologias. Este programa se coordena com outros, em quatro setores subordinados ao DOE: Energia Eficiente e Renovável, Energia Fóssil, Energia Nuclear e Ciência (DOE, 2011). De acordo com Matos (2009), portanto, os EUA orientam sua ação para examinar, ampliar e legitimar a fabricação, o transporte e o armazenamento de hidrogênio e da metodologia das células a combustível.

Nos últimos 10 anos, o DOE pôs em funcionamento o Programa de Células a Combustível, com o qual obtiveram avanços quanto à diminuição dos custos para produzir hidrogênio a partir de gás natural e de recursos renováveis. Com o uso da tecnologia de reforma do gás natural, o custo de produção compete, por exemplo, com os da produção da gasolina. Além disso, o Departamento trabalha na identificação de materiais que oferecem melhora de 50\% na capacidade de armazenagem de hidrogênio. Com o intuito de dar validade a essa tecnologia, o DOE visa, ainda, a inclusão de 140 veículos que se movem a partir de hidrogênio (LABORDE et al., 2010). Os recursos que o DOE e o Departamento de Transportes dos EUA mantêm referentes à pesquisa sobre o hidrogênio, recursos humanos e células a combustíveis cresceram no período de 2005 a 2008, se mantiveram estáveis no ano de 2009 e caíram 10\% no ano de 2010 (LELLIS et al., 2010).

Em novembro de 2003, os EUA, por meio do DOE, estabeleceram parceria para a economia do hidrogênio, um esforço internacional com a proposta de organizar e de implantar a pesquisa e o desenvolvimento, as atividades de utilização e de demonstração pertinentes ao hidrogênio e as tecnologias envolvidas nas células a hidrogênio. Os EUA, juntamente com a China e o Japão, lideram as pesquisas de processo de produção de hidrogênio nos últimos 20 anos, com $16 \%, 16 \%$ e 14\%, respectivamente, do total de pesquisas (LELLIS et al., 2010). Segundo Bezerra Filho (2008), a Coréia do Sul, que aparece em quarto lugar no ranking (5\%), conta com uma das maiores usinas de energia de células a combustível do mundo.

Os EUA apresentam uma preocupação acentuada quanto à busca de novas fontes energéticas, oriundas do hidrogênio, como o Programa de Células a Combustível. Com este programa, conseguiram avançar no intuito de diminuir os custos para produzir hidrogênio a partir de gás natural e de recursos renováveis. Desta forma, é notável o interesse por parte dessa nação na busca por medidas que visem a tecnologia do hidrogênio, tornando-a atrativa financeiramente.

\subsection{O HIDROGÊNIO NO JAPÃO}

O Japão foi pioneiro ao possuir um programa em pesquisa e desenvolvimento sobre hidrogênio e células a combustível, sendo investidos US\$ 153,34 milhões no período 1992-2002. Em 2003, foi disseminado o plano New Hydrogen, que focava em sua comercialização. No ano de 2005, foram orçados US\$ 33,7 milhões em projetos de investigação sobre hidrogênio em veículos com células a combustível, desenvolvidos pelo New Energy and Industrial Technology Development Organization (NEDO). O NEDO também aprimora estruturas fundamentais do procedimento de armazenagem de hidrogênio. O NEDO e o Ministery of Economy, Trade and Industry (METI) são as instituições que mais têm projetos em hidrogênio e em células a combustível no país.

No país, existe a pressão oriunda de legislação ambiental, concomitante a isto, a população depende dos recursos fósseis não disponíveis. Estes fatos motivaram o país a definir estratégias para o setor de energia. Para isto foram desenvolvidas novas baterias, células a combustível e base de construção para estas. O Japão quer, com isto, apresentar uma inovação no conceito de combustíveis limpos e de baixo consumo (LABORDE et al., 2010; LELLIS et al., 2010). 
Grandes fabricantes de automóveis japoneses utilizaram as células a combustível em alguns modelos de veículos, obtendo bons resultados de desempenho: autonomia de $620 \mathrm{~km}$, num determinado modelo; e mais de $830 \mathrm{~km}$ noutro modelo, diante da incorporação de nova tecnologia. Em relação à distribuição percentual das patentes sobre as células a combustível no período 1989-2008, há a representatividade do Japão $(67,19 \%)$, dos EUA $(12,73 \%)$, da Alemanha $(6,18 \%)$, da Coreia do Sul $(5,15 \%)$ e da China $(4,56 \%)$. O Brasil aparece com apenas $0,02 \%$ no período (LELLIS et al., 2010).

O Japão, por ser um país altamente dependente de recursos fósseis, vê a necessidade da busca por novas alternativas de geração de energia. No entanto, outro fator acarreta ainda uma maior relevância quanto ao tema, que são as questões ligadas à forte legislação ambiental do país. Estes fatos levaram o Japão a realizar altos investimentos nesse setor, tornando-o um dos maiores investidores em hidrogênio e em células a combustível.

\subsection{O HIDROGÊNIO NA EUROPA}

Na Europa, o primeiro grande projeto na área de hidrogênio foi o Clean Urban Transport for Europe (CUTE), que teve por finalidade básica colocar em circulação 27 ônibus de transporte público abastecidos com célula a combustível. Esse projeto começou a funcionar no ano de $2000 \mathrm{e}$ foram investidos 52 milhões de euros (LABORDE et al., 2010). Como principais resultados do projeto CUTE, no período 2003-2005, estão a eficiência de $90 \%$ obtida e o número de mais de 4 milhões de passageiros transportados e nenhum acidente grave, além disso, se obteve uma quantidade de diesel substituído por hidrogênio da ordem de 450.000 litros (LABORDE et al., 2010).

Há, na Europa, outros projetos com o intuito do desenvolver as tecnologias de geração de energias limpas, como o The European Hydrogen Energy Roadmap (HyWays). Este projeto desenvolveu-se entre 2004 e 2007, integrado por institutos de pesquisa, por indústrias e pela Comissão Europeia, tendo como objetivo desenvolver um mapa da rota para a introdução do hidrogênio no sistema energético europeu e dando prioridade ao setor de transporte (LABORDE et al., 2010).

O Projeto MedHysol tem como finalidade produzir hidrogênio, empregando a energia solar. Numa primeira etapa, deve construir uma plataforma piloto para produção de hidrogênio a partir da energia obtida do sol na forma de energia elétrica (10-100 kW). O hidrogênio pode ser produzido da água a partir da energia elétrica gerada da luz solar, salientando que a potencialidade da costa do mediterrâneo no desenvolvimento de energia solar é de 100 vezes a demanda energética do mundo. Posteriormente, numa segunda etapa, o projeto aplicará tecnologias eficientes e de baixo custo para sítios piloto de maior escala (1 a 1.000 MW). O hidrogênio é obtido então pela eletrólise da água (LABORDE et al., 2010).

$\mathrm{Na}$ Espanha estão concentrados os maiores números de grupos de empresas envolvidas nessa tecnologia. Este país, como integrante da UE, também participa das políticas desenvolvidas no continente (LABORDE et al., 2010). Entre 2001 e 2011, há expectativa de que a totalidade do financiamento da UE, não levando em consideração as estimativas nacionais, seja de US\$ 3,3 bilhões, sendo que metade desses recursos é de origem privada.

Por fim, segundo CGEE (2010), identifica-se, observando documentos oficiais de países com envolvimento na tecnologia do hidrogênio, que sua motivação principal é a capacidade de geração de hidrogênio a partir de diversas fontes e com mínimos impactos ambientais. Os países que priorizam essa tecnologia são aqueles que demandam muita energia e, consequentemente, poluem muito e emitem um volume maior de gases de efeito estufa. A geração de hidrogênio apresenta-se como uma alternativa ao consumo de fontes energéticas fósseis. As tecnologias do hidrogênio têm amplo potencial de desenvolvimento tecnológico, de diminuição de despesas e de aumento de utilizações. Porém, ainda não estão tecnicamente consolidadas. Há expectativa de que, nos próximos anos, os preços caiam em proporção significativa devido aos ganhos de escala e à maturidade tecnológica.

\section{OS INVESTIMENTOS EM HIDROGÊNIO NO BRASIL}

Os investimentos em hidrogênio no Brasil estão direcionados para dois segmentos: gerar energia nas células a combustível para suprir veículos e unidades estacionárias e gerar hidrogênio com o objetivo de produzir um combustível com um menor teor de enxofre (MME, 2012). Nesta seção são analisados os investimentos estatais em hidrogênio no país.

\section{I OS INVESTIMENTOS ESTATAIS}

$\mathrm{Na}$ América Latina, o Brasil lidera as pesquisas em tecnologia de hidrogênio. No período 1999-2007, os investimentos brasileiros, de origem pública e privada somaram, aproximadamente, 
$\mathrm{R} \$ 134$ milhões, que representam $25 \%$ a $35 \%$ dos investimentos individuais da Rússia, da Índia, da China ou da Coreia do Sul e de 3\% a 5\% do que é investimento no Japão, na UE ou nos EUA (CGEE, 2010). Embora tenha ocorrido uma elevação das pesquisas nesta tecnologia, os recursos destinados por parte do governo federal são reduzidos se comparados com os demais países.

Segundo Matos (2009), o Brasil tem duas políticas com a finalidade de incremento da economia do hidrogênio, sendo uma delas coordenada pelo MCT e a outra pelo Ministério das Minas e Energia (MME). Em 2002, o Brasil instituiu o Programa Brasileiro de Sistemas Células a Combustível (ProCac), sendo implantado em 2004 e tendo como objetivo promover ações que deem viabilidade para o desenvolvimento nacional dessa tecnologia. Esse programa foi arquitetado em redes cooperativas de pesquisa e desenvolvimento, sendo que três delas já se encontram em funcionamento: Rede de Células PEM, Rede de Células de Óxido Sólido e Rede de Combustíveis e Hidrogênio (FOSTER et al., 2011). Em 2005, o ProCac foi transformado no Programa de Ciência, Tecnologia e Inovação para uma Economia do Hidrogênio (ProH2) e está inserido no Plano de Ação para Ciência, Tecnologia e Inovação (PACT\&I). Seu objetivo é o desenvolvimento de ações que permitirão criar tecnologia brasileira nos sistemas de energia, tendo-se por base as células a combustível para a produção de energia elétrica de forma eficiente e com menor impacto ambiental (LABORDE et al., 2010).

Segundo CGEE (2010), o ProH2 considera diretrizes específicas que consistem em: (1) Conceber a operação das redes cooperativas de Pesquisa, Desenvolvimento e Inovação (PD\&I), envolvendo universidades, institutos de pesquisa, núcleos de pesquisa, incubadoras e empresas; (2) Revitalizar e melhorar a infraestrutura da investigação por parte dos estabelecimentos abrangidos no ProH2; (3) Promover o desenvolvimento e o treinamento de recursos humanos, dando destaque à pós-graduação no país e aprimoramento em núcleos de destaque no assunto no Brasil e em outros países; (4) Implantar projetos de esclarecimento de distintos aparelhos de células a combustível e metodologias da produção de hidrogênio, dando ênfase às metodologias desenvolvidas no programa ProH2; (5) Implementar projetos demonstrativos associados, privilegiando o uso dos combustíveis renováveis brasileiros, destacando especialmente a reforma do etanol; (6) Promover a colocação de cláusulas e moldes a fim da afirmação dos produtos, procedimentos e serviços atinentes às metodologias de hidrogênio e células a combustível; (7) Conservar e disponibilizar documentos sobre os grupos de observação, infraestrutura, planos e empresas abrangidas com os procedimentos do hidrogênio no país.

Para Laborde et al. (2010), o ProH2, portanto, pretende promover a formação e o treinamento de recursos humanos, com ênfase em pós-graduação no Brasil e pós-doutorado no Brasil e no exterior. Além disso, busca implantar projetos de demonstração de aparelhos de células a combustível e de tecnologias da produção de hidrogênio (prioridade às tecnologias criadas no ProH2), entre outros.

O Centro de Gestão e Estudos Estratégicos (CGEE) coordenou a participação de pesquisadores e de executivos ligados às instituições governamentais e empresariais com a finalidade de se chegar a propostas de atuação na área da economia do hidrogênio: produção, logística e sistemas de utilização. Essas propostas têm o prazo de 15 anos, divididas em três níveis: ações de curto prazo, de 0 a 5 anos; ações de médio prazo, de 5 a 10 anos; e ações de longo prazo, de 10 a 15 anos (CGEE, 2010).

\subsection{OUTROS PROJETOS}

Há outros projetos sobre hidrogênio e células a combustível com fontes de financiamento distintas. $\mathrm{O}$ primeiro deles se destina à construção de um ônibus urbano elétrico híbrido de 12 metros. Este projeto foi financiado por FINEP, PETROBRAS, CNPq e Fundação de Amparo ao Estudo do Estado do Rio de Janeiro (FAPERJ). O ônibus foi desenhado pelo Instituto Alberto Luiz Coimbra de Pós-Graduação e Pesquisa de Engenharia, da Universidade Federal do Rio de Janeiro (COPPE/UFRJ), e as células a combustível construídas pela empresa brasileira Eletrocel (LABORDE et al., 2010).

O segundo projeto consistiu, em julho de 2009, no funcionamento de um ônibus alimentado por células a combustível pela Empresa Metropolitana de Transportes Urbanos de São Paulo (EMTU/SP). O ônibus foi construído pela própria empresa e contou com apoio de outras, entre elas a MARCOPOLO, fabricante de carrocerias e de seus componentes, e a PETROBRAS Distribuidora, integradora e operadora da estação de abastecimento de hidrogênio (LABORDE et al., 2010).

$\mathrm{O}$ terceiro projeto se relaciona à montagem e à operação de uma célula a combustível capaz de produzir energia, utilizando o etanol com potência mínima de $5 \mathrm{~kW}$. Este projeto é financiado pela FINEP e conta com sócios, como o 
Instituto Nacional de Tecnologia (INT), o Instituto de Investigações Energéticas e Nucleares (IPEN) e o Centro de Investigações de Energia Elétrica (CEPEL) (LABORDE et al., 2010).

A produção de hidrogênio no Brasil tem finalidade industrial de acordo com Assis et al. (2008). Neste aspecto, cabe destacar também o papel desempenhado pela empresa PETROBRAS, que vem destinando recursos no aprimoramento dessa tecnologia, como é o caso da implantação da Unidade de Geração de Hidrogênio (UGH) na Refinaria Alberto Pasqualini (REFAP), situada em Canoas (RS). O objetivo da Unidade, segundo REFAP (2011), é fornecer hidrogênio para a Unidade de Hidrotratamento (UHDT) com o intuito de "reduzir os teores de enxofre e de componentes instáveis no combustível, o que possibilita a Refap produzir um diesel mais estável e menos poluente". Segundo dados da Refinaria, a capacidade de produção é de $550 \mathrm{mil} \mathrm{Nm}^{3}$ / dia de hidrogênio com $99,9 \%$ de pureza, com cargas de gás natural ( $224.880 \mathrm{Nm}^{3} /$ dia) ou gás de refinaria $\left(302.000 \mathrm{Nm}^{3} / \mathrm{dia}\right)$. A PETROBRAS tem realizado pesquisas na área energética com o intuito de reduzir a produção de compostos tóxicos, como é o exemplo da célula a combustível de hidrogênio (PETROBRAS, 2011).

A PETROBRÁS já produz o hidrogênio a partir do processo denominado reforma a vapor do gás natural, GLP (gás de cozinha). A capacidade da planta instalada foi de 10 milhões de Nm3 no ano de 2008 e deverá ser aumentada, no mínimo, em $400 \%$ nos anos seguintes para suprir a demanda por combustíveis, tanto diesel como gasolina produzidos com um menor teor de enxofre (10ppm), seguindo determinações ambientais (RODRIGUES et al., 2010).

O Brasil tem a sua disposição uma variada matriz energética, tendo em vista todas as alternativas que dispõe para a produção de combustíveis fósseis e renováveis. Simultaneamente, o crescimento dos setores econômicos implicará numa maior demanda por energia, em médio e logo prazo, o que constitui um ambiente adequado para o ingresso gradativo do hidrogênio com fins comerciais.

\subsection{A PRODUÇÃO DE HIDROGÊNIO E DE CÉLULAS A CỎMBUSTIIVEL NO BRASIL}

Araújo (2009) apresenta as prioridades, para o Brasil, de quando acontecerá a utilização comercial do hidrogênio, oriundo de fontes distintas, sendo elas a reforma do etanol e o uso de biomassa, a eletrólise da água, a reforma do gás natural e processos alternativos. Segundo o autor, já para o ano de 2015 ocorrerá o uso comercial do hidrogênio produzido pela reforma do gás natural, sendo que em 2020 ocorrerá o uso comercial do hidrogênio obtido pela eletrólise da água. Para o ano de 2025 está prevista a comercialização do hidrogênio oriundo da reforma do etanol e do uso de biomassa. Por fim, para o ano de 2030, processos alternativos para obtenção de hidrogênio entram em pauta.

No Brasil, há três plantas de células a combustível em funcionamento, sendo duas delas no estado do Paraná e uma no Rio de Janeiro. A potência dessas células é de $200 \mathrm{~kW} / \mathrm{h}$ cada e o que as mantêm em funcionamento é o gás natural reformado a hidrogênio (ASSIS et al., 2008). Segundo Foster et al. (2011), o processo de produção de células a combustível ainda se encontra na fase inicial, mas existem pesquisas sendo desenvolvidas no que diz respeito a estes sistemas. A tecnologia nacional dispõe de células com poder de geração de energia de $25 \mathrm{~W}$ a $5 \mathrm{~kW}$, consideradas de potência baixa, e de $5 \mathrm{~kW}$ até 75 $\mathrm{kW}$, que estão num estágio de desenvolvimento. Futuramente, o mercado ofertará sistemas de 250 kW. Conforme apresenta Bezerra Filho (2008), em Curitiba (PR), a empresa Brasil H2 Fuel Cells Energy está comercializando células a combustível tanto estacionárias quanto móveis, com potência de $12 \mathrm{~W}$ a $5 \mathrm{~kW}$.

Em relação à matriz energética brasileira, em 2003, a oferta interna de combustíveis veiculares totalizou pouco mais de 1 milhão de barris por dia, cuja distribuição, indicada na matriz de combustíveis veiculares, apresenta participação majoritária do diesel $(56,8 \%)$ e da gasolina $(35,6 \%)$ (CGEE, 2010). O hidrogênio é utilizado na melhoria dos combustíveis e, no caso do diesel, ele é usado para retirar o enxofre existente, tornando menor a emissão de poluentes, como os derivados do enxofre.

No ano de 1996, o Conselho Nacional do Meio Ambiente (Conama) implantou o Programa de Controle de Poluição do Ar por Veículos Automotores (Proconve) com a finalidade de diminuir as emissões oriundas dos automóveis no Brasil. Esta instrução foi uma das causas para que o catalisador se tornasse imprescindível na produção de veículos. O Proconve tem duas hierarquias, uma voltada para automóveis leves, chamados de passeio, e outra voltada para automóveis pesados (CRUZ, 2008).

Nos anos 1990, as fábricas de veículos já produziam motores com coeficientes de emissão abaixo daqueles solicitados em 1993, ano em que se começou a controlar a emissão para veículos deste tipo, com a adoção de diferentes etapas. 
Nessa ocasião, a definição para emissão de gases (fase 1) e de partículas (fase 2) não foi estabelecida por lei. A fim de acolher os limites estabelecidos pela fase 3, que entrou em vigor a partir de 1994, foram criados modelos inovadores de motores com o objetivo de reduzir o gasto de combustível, elevar a força e mitigar as emissões de gases de óxido de nitrogênio com inovações tecnológicas (CRUZ, 2008).

No ano de 1998, vigorou a fase 4, reduzindo ainda mais os limites instituídos na etapa anterior. Durante a inserção dessa fase, os produtos de diesel brasileiro tiveram seus níveis de enxofre reduzidos para os presentes $500 \mathrm{ppm}$ para serem utilizados em cidades e $2.000 \mathrm{ppm}$ para serem utilizados no interior (CRUZ, 2008).

No ano de 2002, o Conama anunciou a Resolução 315/2002, regulamentando as novas fases do Proconve, fases 5 e 6 . A grande parte deste documento impunha ônus aos poluentes emitidos por motores do ciclo Otto e Diesel, distinguindo experimentos e aplicando normas direcionadas na sua maior parte para a indústria de veículos. Este documento menciona no Artigo 18, Parágrafo 2, que os combustíveis vendidos terão a obrigação de ter peculiaridades adaptadas e ajustadas com as técnicas a serem tomadas e serem disponíveis nos prazos previstos na Resolução (CRUZ, 2008).

Dessa forma, mesmo a resolução não especificando declaradamente os graus de enxofre no diesel, ela vincula o combustível aos níveis de emissão permitidos para os motores de combustão. Ainda que a Resolução 315 não recomende os índices de enxofre no óleo, os fabricantes de combustíveis debateram a legitimidade jurídica do regulamento, tendo em vista que o mesmo sobre os ingredientes que compõem os combustíveis é de envergadura apenas e exclusivamente da Agência Nacional do Petróleo (ANP) (CRUZ, 2008).

Mesmo com a contenda a propósito do tema, a etapa 5 do Proconve iniciou em janeiro do ano de 2006 sem maiores agravos, tendo em vista que o incremento da técnica dedicada para os novos automóveis admitia o uso do diesel com no máximo 500 ppm, não ultrapassando os limites de emissão estabelecidos. No entanto, a indústria de veículos noticiou que para atender a etapa 6 daquele programa, antevisto para o mês de janeiro do ano de 2009, o diesel não poderia apresentar um nível maior do que $50 \mathrm{ppm}$ de enxofre. No ano de 2007 acabou a discussão, momento em que a ANP anunciou a Resolução ANP 32, de dia 16 de outubro de 2007, que regulamentava os coeficientes máximos de enxofre, recomendando limites para que os fabricantes atendessem a Resolução. Este limite seria combinado com o começo da etapa 6 do Proconve (CRUZ, 2008).

Cruz (2010, p. 26) afirma que:

Além dos investimentos atuais, novos montantes devem ser investidos na redução dos níveis de enxofre no diesel, uma vez que o Conama aprovou no final de 2008 uma nova resolução limitando o enxofre presente no diesel em 10ppm, introduzindo uma nova fase no Proconve (P-7). Esta nova fase entraria em vigor a partir de 2012.

Neste sentido, segundo MME (2012), desde janeiro de 2012, o denominado Diesel S50 está sendo ofertado Brasil. O objetivo da adoção desta tecnologia é reduzir a emissão dos gases que poluem o meio ambiente e ao mesmo tempo dar mais eficiência aos veículos. Essa ação atende as Fases P-7 e L-6 contidas do Proconve, normatizada pela Resolução do Conama. O Proncove é um empreendimento do Conama, sendo que o Instituto Brasileiro de Meio Ambiente (IBAMA) é responsável por sua coordenação, tendo por meta a redução dos limites de emissões de gases poluentes, a maior eficiência aos veículos.

A produção nacional de diesel não está pronta para abastecer o mercado com combustíveis deste tipo pela PETROBRAS, companhia que detém o monopólio da fabricação do diesel brasileiro. A PETROBRAS empenhou-se em importar esse combustível com nível de 50 ppm de enxofre, denominado diesel S-50. A medida adotada abrangeria somente automóveis fabricados de janeiro de 2009 em diante, tendo em vista que, de acordo com a companhia, para os veículos produzidos anteriormente, a adoção da medida não traria benefícios pelo fato de não possuírem tecnologia compatível com o novo combustível.

Anualmente, em torno de 120 mil novos caminhões ingressam nas rodovias e estradas do país. Esse fato faz com que haja pressão para a importação do diesel com menor teor de enxofre, o S-50. A PETROBRAS tem trabalhado na atualização 14 refinarias (US\$ 6,5 bilhões), especialmente, para a edificação de unidades de hidrodessulfurização do diesel (HDT) e de unidades de geração de hidrogênio (UGH). Assim, será possível suprir o consumo demanda de diesel S-50, não necessitando a sua importação (PETROBRAS, 2011).

Novas legislações na Europa e nos EUA e novas regras para os graus de enxofre no diesel do Brasil elevam a precisão por procedimentos de hidrotratamento. Muitas refinarias ao redor do mundo se empenharam em tornar suas unidades 
de hidrotratamento mais modernas ou construir novas. A quantia de hidrogênio demandado para atuar nestas unidades se amplia em grandeza ascendente. No processo de hidrotratamento, cada um dos átomos de enxofre retirado esgota dois átomos de hidrogênio, derivando na constituição de H2S e, depois de novo tratamento, resultando em vapor de água e sulfeto de zinco (ZnS) (CRUZ, 2010).

Em relação aos teores de enxofre no diesel, na América do Sul, na África e em parte da Ásia, os níveis de enxofre contidos no petróleo estão entre 1.000 e $12.000 \mathrm{ppm}$. Contudo, na maior parte da América do Norte, esta medida está entre 10 e 15 ppm. A Austrália aparece com 50 ppm e o Japão com 10 a 50 ppm (CRUZ, 2010).

Por fim, no Brasil, o MCT tem investido em pesquisas em hidrogênio e em células a combustível com o objetivo de reduzir os gases que provocam o efeito estufa e também com o intuito de garantir a segurança energética.

\section{CONSIDERAÇÕES FINAIS}

As células a combustível e os avanços tecnológicos para geração de hidrogênio se encontram em estágio avançado em alguns países. No Brasil, existem diversos estudos, como Moreira (2005), Santos (2008), Rohrich (2008), Bernardi Junior (2009), Braga (2009), Matos (2009), Cruz (2010) e D'Alessandro (2011), entre outros, que destacam a intenção de tornar a tecnologia do emprego direto do hidrogênio em células a combustível e, com isso, permitir a conversão de hidrogênio em energia para utilização em veículos e na geração de energia elétrica em estações estacionárias. Também tem sido realizados investimentos em hidrogênio para a diminuição dos níveis de enxofre no diesel. A indústria automobilística vem atendendo às Resoluções, criadas desde 2002, com novos motores e tecnologias.

O hidrogênio surge, desta forma, como uma alternativa energética, podendo ser gerado do excedente de força das usinas hidrelétricas para, posteriormente, gerar energia elétrica em localidades distantes das linhas de transmissão, já que pode ser acondicionado e transportado até as distantes unidades geradoras. $\mathrm{O}$ hidrogênio é utilizado cada vez mais para tornar o diesel menos poluente e aceitável nos grandes centros urbanos. Ele também entra na composição de componentes eletrônicos, farmacêuticos, entre outros, destacando-se na forma de promover a geração de energia limpa, células a combustível ou melhoria de combustíveis (diesel). O hidrogênio também entra na composição de adubos e de fertilizantes utilizados, por exemplo, na cana de açúcar, que, por sua vez, gera açúcar e álcool.

No mundo, recursos públicos e privados vêm sendo aplicados nesta tecnologia, que permite um aproveitamento do hidrogênio na forma de energia elétrica gerada a partir do mesmo quando em contato com as células a combustão. Para isto, vários modelos de células, com diferentes procedimentos para geração de energia e matérias para sua construção, têm sido produzidos e pesquisados.

Como ocorreu na transição do carvão para o petróleo, está sendo desencadeada a era do hidrogênio, que entra na matriz energética mundial para consolidar ainda mais as nações na geração de energia, principalmente, em povoados distantes e em órgãos que não podem sofrer interrupção de fornecimento energético, como hospitais. $\mathrm{O}$ principal limitante para uma economia do hidrogênio sustentável e economicamente viável ainda se encontra no custo das células a combustível, necessárias para que o hidrogênio, vetor energético, seja utilizado como energia elétrica. Existe, ainda, a questão política que envolve grandes empresas e países com suas economias alicerçadas em combustíveis fósseis.

Os investimentos estatais brasileiros em hidrogênio estão direcionados para dois segmentos: sua utilização direta em células a combustíveis, por exemplo, em computadores e em veículos (ônibus) e para tornar os combustíveis menos poluentes (diesel). Por fim, a preocupação com o meio ambiente tem suscitado a procura por combustíveis mais eficientes e menos poluentes. Neste sentido, os investimentos estatais brasileiros em hidrogênio estão buscando a redução dos impactos ambientais ocasionados por combustíveis fósseis.

\section{REFERÊNCIAS BIBLIOGRÁFICAS}

ALMEIDA A. T. de. O hidrogênio como combustível. Lisboa: Faculdade de Ciências e Tecnologia da Universidade de Coimbra, 2005. Disponível em: http://www.eq.uc.pt/inovar/hidrogenio.pdf. Acesso em: 10 jan. 2012.

ARAÚJO, S. C. de S. A energia de hidrogênio: desafios. Brasília: MME, 2009. Disponível em: http:// www.emtu.sp.gov.br/EMTU/pdf/p14mme.pdf. Acesso em: 15 fev. 2012

ASSIS, Adilson J. et al. Produção de hidrogênio a partir da fermentação de compostos orgânicos. In: SEMINÁRIO DE IC, 12, 2008, Uberlândia. Anais... 
Uberlândia: UFU, 2008.

BERNARDI, Junior P. Alternativas para a produção de hidrogênio nas regiões brasileiras visando a geração de energia elétrica distribuída. 2009. Tese (Doutorado em Tecnologia Nuclear) - Universidade de São Paulo, São Paulo, SP, 2009.

BEZERRA FILHO, J. G. Células a combustível a hidrogênio: estudo de caso comparativo com um motor a combustão. 2008. Trabalho de Conclusão de Curso (Curso de Graduação em Tecnologia Mecatrônica) - Instituto Federal de Educação, Ciência e Tecnologia, Fortaleza, CE, 2008.

BRAGA, J. M. F. Análise da viabilidade econômica da integração de sistemas de célula a combustível, nas plantas de cloro-soda, para utilização do hidrogênio gerado no processo. 2009. Tese (Doutorado em Tecnologia de Processos Químicos e Bioquímicos) - Universidade Federal do Rio de Janeiro, Rio de Janeiro, RJ, 2009.

CARVALHO, Joaquim Francisco. O Declínio da era do petróleo e a transição da matriz energética brasileira para um modelo sustentável. Tese (Doutorado) - Universidade de São Paulo, São Paulo, SP, 2009.

CENTRO DE GESTÃO E ESTUDOS ENERGÉTICOS. CGEE. Hidrogênio energético no Brasil: subsídios para políticas de competitividade, 2010-2025; tecnologias críticas e sensíveis em setores prioritários. Brasília: Centro de Gestão e Estudos Estratégicos, 2010.

CRUZ, F. E. da. Produção de hidrogênio em refinarias de petróleo: avaliação energética e custo de produção. 2010. Dissertação (Mestrado) - Universidade de São Paulo, São Paulo, SP, 2010.

D'ALESSANDRO M. Metodologia de gerenciamento de risco do hidrogênio. 2011. Dissertação (Mestrado Profissional em Tecnologia) - Instituto de Tecnologia para o Desenvolvimento, Curitiba, PR, 2011.

DEPARTMENT OF ENERGY. DOE. Energy sources. Hydrogen. Disponível em: http://www.energy. gov/energysources/hydrogen.htm. Acesso em: 9 maio 2011.

FOSTER, Maria das G. et al. Estruturação da economia do hidrogênio no Brasil. Brasília: CGEE, 2011. Disponível em: http://cncti3.cgee.org.br/ Documentos/Seminariosartigos/Areasintnacional/
DraMaria\%20das\%20Gracas\%20Silva\%20Foster.pdf. Acesso em: 20 abr. 2011.

GATTO, B. B. Panorama do setor elétrico brasileiro e maior inserção de formas renováveis de geração de energia no país. 2010. Monografia (Curso de Engenharia Elétrica com ênfase em Sistemas de Energia e Automação) - Universidade de São Carlos, São Carlos, SP, 2010.

LABORDE, Miguel A. et al. Potencialidades del hidrogeno como vector de energia em iberoamérica. Buenos Aires: Ediciones CYTED, 2010.

LELLIS, Vera Lúcia Maia et al. Relatório final de atividades - Metas 4 e 5: Projeto UTILH2. Rio de Janeiro: Instituto Nacional de Tecnologia, 2010.

MATOS M. B. de. Investimentos financeiros em projetos de células a combustível e hidrogênio no Brasil. 2009. Dissertação (Mestrado em Engenharia Mecânica) - Universidade Estadual de Campinas, Campinas, SP, 2009.

MINISTÉRIO DE MINAS E ENERGIA. MME. Disponível em: http://www.mme.gov.br/mme/noticias/destaque2/destaque_298.html. Acesso em: 6 fev. 2012.

MOREIRA, Leila Burgos de Carvalho. Avaliação dos aspectos ambientais da geração de energia através de termoelétricas a gás natural. 2005. Dissertação (Mestrado em Gerenciamento e Tecnologias Ambientais no Processo Produtivo) - Universidade Federal da Bahia, Salvador, BA, 2005.

PETROBRAS. Energia e tecnologia. Outras fontes de energia: hidrogênio combustível. Disponível em: http://www.PETROBRAS.com.br/pt/energia-e-tecnologia/fontes-de-energia/outras-fontes-energia/ default.asp. Acesso em: 19 maio 2011.

REFINARIA ALBERTO PASQUALINI. REFAP. Unidades. UGH - Unidade de Geração de Hidrogênio. Disponível em: http://www.refap.com.br/ refap_unidades.asp. Acesso em: 12 maio 2011.

RIFKIN, Jeremy. Economia do hidrogênio. São Paulo: Book do Brasil Editora Ltda., 2003.

RODRIGUES, Glenda Rangel et al. Fuel quality (and air quality) vs. greenhouse gases emissions - The Challenge of Oil Refines. Paper 2010-830AWMA. 2010. 
ROHRICH, S. S. Descarbonização do regime energético dominante: perspectivas para a economia do hidrogênio no Brasil. 2008. Tese (Doutorado) Universidade Estadual de Campinas, Campinas, SP, 2008.

SANTOS, A. M. R. Tendências tecnológicas das células a combustível para uso do hidrogênio derivado de petróleo e gás natural. 2008. Tese (Doutorado) - Universidade Estadual de Campinas, Campinas, SP, 2008. 